\title{
ENSINO COLETIVO DE VIOLÃO: um relato de experiência sobre o ensino da música no currículo das turmas de Anos Iniciais
}

\author{
HENRIQUE SOARES BRAGAMONTE \\ Especialista em Educação Musical. Professor de História. \\ ORCID: https://orcid.org/0000-0001-8144-9886. E-mail: henriquebragamonte@gmail.com

\section{PATRÍCIA LUCIENE DE ALBUQUERQUE BRAGAMONTE} \\ Mestre em Políticas Públicas e Gestão Educacional da Universidade Federal de Santa Maria. \\ Pesquisadora do GEPE - Grupo de Estudo e Pesquisa em Educação Especial e Inclusão da \\ UFSM. ORCID: https://orcid.org /000-0001-7761-0921 E-mail: patriciabragamonte@gmail.com
}




\section{ENSINO COLETIVO DE VIOLÃO: um relato de experiência sobre o ensino da música no currículo das turmas de Anos Iniciais}

O presente artigo tem como tema a música como conteúdo curricular na Educação Básica. Este trabalho trata-se de um relato de experiência sobre o ensino coletivo de violão no currículo das turmas de anos iniciais que vem sendo realizado desde 2015, na Escola Vida, situada no município de Alegrete/RS. A pesquisa foi realizada no turno regular, com alunos das turmas do $3^{\circ}$ ao $5^{\circ}$ ano, que se encontram na faixa etária entre 8 a 11 anos, com o objetivo de refletir sobre o ensino coletivo de violão na aprendizagem musical de alunos dos anos iniciais. Ao concluir este trabalho percebeu-se que o ensino coletivo de violão proporciona o desenvolvimento de experiências musicais colaborativas e autonomia dos alunos em suas aprendizagens, desafiando o educador musical na criação de propostas criativas para a mediação das aprendizagens de seus alunos.

Palavras chave: Educação Musical. Currículo. Ensino Coletivo de Violão. Educação Básica.

\section{COLLECTIVE TEACHING OF VIOLÃO: a report of experience on the teaching of music in the curriculum of the years}

This article deals with music as a curricular content in Basic Education. This work is an experience report about the collective teaching of guitar in the curriculum of the classes of initial years that has been carried out since 2015, in Escola Vida, located in the city of Alegrete / RS. The research was carried out in the regular shift, with students from the 3rd to 5th grades, who are in the age group between 8 and 11 years, with the purpose of reflecting on the collective teaching of guitar in the musical learning of students of the initial years. At the conclusion of this work it was noticed that the collective teaching of guitar provides the development of collaborative musical experiences and students 'autonomy in their learning, challenging the musical educator in the creation of creative proposals for the mediation of their students' learning.

Keywords: Musical Education. Curriculum. Collective Teaching of Guitar. Basic education.

\section{ENSEÑA COLECTIVA DE VIOLÓN: un relato de experiencia sobre la enseñanza de la música en el currículo de las turmas de años inicial}

El presente artículo tiene como tema la música como contenido curricular en la Educación Básica. Este trabajo se trata de un relato de experiencia sobre la enseñanza colectiva de guitarra en el currículo de las clases de años iniciales que viene siendo realizado desde 2015, en la Escuela Vida, situada en el municipio de Alegrete / RS. La encuesta fue realizada en el turno regular, con alumnos de las clases del $3^{\circ}$ al $5^{\circ}$ año, que se encuentran en el grupo de edad entre 8 a 11 años, con el objetivo de reflexionar sobre la enseñanza colectiva de la guitarra en el aprendizaje musical de alumnos de los años iniciales. Al concluir este trabajo se percibió que la enseñanza colectiva de guitarra proporciona el desarrollo de experiencias musicales colaborativas y autonomía de los alumnos en sus aprendizajes, desafiando al educador musical en la creación de propuestas creativas para la mediación de los aprendizajes de sus alumnos.

Palabras-clave: Educación Musical. Plan de estudios. Enseñanza Colectiva de Guitarra. Educación básica. 


\section{ENSINO COLETIVO DE VIOLÃO: um relato de experiência sobre o ensino da música no currículo das turmas de Anos Iniciais}

\section{Introdução}

Apesar do estudo da Música comprovadamente, através dos estudos de Howard Gardner sobre as Inteligências Múltiplas (GARDNER, 1995), ter uma posição de destaque por ser uma linguagem própria e no âmbito legal, com a Lei no 11.769/2008, ser garantida como "conteúdo obrigatório" (BRASIL, 2008, s/p), ainda percebemos muitos obstáculos na universalização do acesso à Educação Musical nas escolas brasileiras e com isso, "quem tem feito a educação musical de nossos jovens [e crianças] são a televisão e o rádio. E esses não visam a qualidade, mas o lucro" (ZAGONEL, 2001, p. 2).

A música vinculada ao ensino de Artes, a prática polivalente de ensino ainda muito presente nos sistemas educacionais brasileiros, a falta de formação adequada dos docentes e a escassez de recursos e materiais são alguns fatores que vêm contribuindo para que a sua implementação na Educação Básica se torne, de certa forma, facultativa ou complementar, através de projetos e programas.

Isso fica mais evidente quando analisamos pesquisas e trabalhos publicados sobre o tema e percebemos que a maior parte das teses, dissertações, trabalhos de conclusão de curso e artigos que foram encontrados (SILVA SÁ, 2016; BARBOSA 2015; OLIVEIRA, 2012; QUEIROZ, 2009; TEIXEIRA BARRETO, 2008) estão relacionados a projetos que aconteceram no contraturno da aula regular, ou seja, fora do currículo, sempre vista como um complemento e não como uma disciplina obrigatória como Português, Matemática, História, etc.

Também as pesquisas de Hentschke (1993), Penna (2002), Arroyo (2003), Hirsch (2007) e Ahmad (2011), que buscam investigar as realidades musicais nos contextos escolares da Educação Básica, apontam para uma carência da Educação Musical enquanto prática curricular.

Como afirma Dias (2010), é importante destacar que muitos desses caminhos da Educação Musical no Brasil são resultado de movimentos vinculados a uma realidade social, produzida por determinações políticas e econômicas. 
o ensino de Artes, em especial da música, não pode ser explicada por si mesma, mas como resultante de um todo social nas suas determinações políticas e econômicas, pois ela decorre das representações de uma sociedade num período histórico, com significações e com aspectos ideológicos do seu momento, expressando uma realidade social (DIAS, 2010, p.16).

Nesse sentido, a Educação Musical tem tido diferentes ênfases no currículo escolar brasileiro, vinculado a diversas reformas educacionais: ora como componente curricular ora como atividade complementar, como afirmam Queiroz e Marinho (2009):

Entre as mais marcantes ações políticas relacionadas a propostas de implementação do ensino de música nas escolas podemos destacar: 1) a aprovação do Decreto n. $1.331 \mathrm{~A}$, de 17 de fevereiro de 1854, primeiro documento que faz menção ao ensino de música na "instrucção publica secundaria" do "Município da Corte" [...] 2) a nova configuração política estabelecida para a música na "Instrucção Primaria e Secundaria do Districto Federal", a partir do Decreto n. 991, já no Brasil republicano (Brasil, 1890); 3) a inserção e a prática do canto orfeônico como base para as aulas de música no ensino secundário, a partir de 1931 para o Distrito Federal - definido pelo Decreto n. 19.890, de 18 de abril de 1931 (Brasil, 1931) - e a sua expansão para outras partes do país, a partir de 1942 com a criação do Conservatório Nacional de Canto Orfeônico - Decreto n. 4.993, de 26 de novembro de 1942 (Brasil, 1942); 4) a definição de "atividades complementares de iniciação artística" como "norma" para a escola de educação básica, instituída pela LDB 4.024/1961, que não faz mais qualquer menção à presença do canto orfeônico na escola regular (Brasil, 1961); 15) o estabelecimento da Educação Artística como campo de formação nas diferentes linguagens das artes na escola, a partir da LDB 5.692/71(Brasil, 1971); 6) a definição do "ensino da arte" como componente curricular obrigatório, estabelecido pela LDB 9.394, de 20 de dezembro de 1996 (Brasil, 1996); 7) e, finalmente, a aprovação da Lei 11.769, de 18 de agosto de 2008, que altera a LDB vigente, determinando o ensino de música como "componente curricular obrigatório" do ensino de arte (Brasil, 2008) (p. 61-62)

Mesmo que seja comum presenciarmos, especialmente em turmas de educação infantil e de anos iniciais, atividades envolvendo ouvir e cantar canções, para a formação de filas, organização do lanche, chamada dos alunos e, principalmente, apresentações nas datas comemorativas, verificamos, através das pesquisas citadas acima e das nossas próprias vivências no cotidiano da 
escola, a ausência do ensino sistemático da música, ou seja, "como uma disciplina atuante dentro dos atuais currículos escolares no Brasil”" (LOUREIROR, 2003, s/p):

a música não é tratada como um tipo de conhecimento a ser ensinado, estudado, compreendido e recriado... mas por outro lado, está sempre presente nos rituais do ambiente escolar, seja nas festas e celebrações, seja na organização e validação do tempo e do espaço das ações que acontecem no dia-a-dia escolar (MATEIRO, 2000, p.2)

Considerando o exposto, o presente artigo tem como tema a música como conteúdo curricular na Educação Básica, cujo objetivo é refletir sobre o ensino coletivo de violão na aprendizagem musical de alunos de anos iniciais. Por tratar-se de uma prática que já vem sendo desenvolvida desde 2015, este trabalho configura-se como um relato de experiência das ações do pesquisador como educador musical na Educação Básica.

\section{Desenvolvimento}

A pesquisa foi desenvolvida nas turmas do $3^{\circ}, 4^{\circ}$ e $5^{\circ}$ ano, da Escola Vida, situada no município de Alegrete, estado do Rio Grande do Sul. As turmas possuem uma média de 20 alunos que se encontram na faixa etária entre 8 a 11 anos. Todas as atividades deste estudo foram desenvolvidas no turno regular de ensino, portanto, no período da tarde.

A prática do ensino coletivo de violão vem sendo realizada com essas turmas desde o ano de 2015. Ela surgiu a partir de uma necessidade dos alunos em explorar e avançar nos conteúdos das aulas de Música, pois, até o presente momento todas as turmas utilizavam somente a Flauta Doce Barroca. Dessa forma, essa é uma pesquisa de natureza qualitativa, com foco em estudo de caso. Appolinário (2004) salienta que pesquisas aplicadas têm o objetivo de "resolver problemas ou necessidades concretas e imediatas" (p. 152).

Durante o contato inicial com o violão já foi possível perceber sua potência pedagógica na aprendizagem musical. Por ser um instrumento muito popular em nossa cultura, aumentou o interesse e a curiosidade dos alunos, criando expectativas no conhecimento de determinados conteúdos da Música e ampliando as experiências em compor, ouvir e tocar.

As aulas foram ministradas duas vezes por semana em cada turma, por um período de 50 minutos. Além da Escola dispor de um vasto aparato tecnológico (data show, notebook, caixas de som, wi-fi) também proporcionou uma professora auxiliar para ajudar na organização dos 
instrumentos, principalmente na afinação dos violões. Também disponibilizou a impressão de partituras e de qualquer material que fosse necessário. Por falta de espaço físico, ainda não foi possível criar uma sala específica para o ensino da Música, por isso, as aulas são ministradas em cada turma e os violões são armazenados nas suas respectivas salas de aula.

É importante dizer que o violão começou a fazer parte da lista de material escolar. Dessa forma, cada aluno tem o seu instrumento. O interessante foi que muitos trouxeram violões de familiares (pais, avós, tios) que estavam guardados em casa, o que confirma o fácil acesso ao instrumento e a sua popularidade em nossa sociedade.

As primeiras dúvidas que foram surgindo - 'O que ensinar nas aulas de Música para que os alunos aprendam a tocar violão?' 'Como ensinar violão para um grupo tão grande?' 'Qual o melhor repertório?' 'Por onde começar a explorar esse instrumento?' e tantas outras mobilizaram a busca de novas metodologias de ensino, pois ainda em nossa cultura musical "o ensino individual [...] é amplamente utilizado [...] como única forma de conseguir um resultado efetivo" (FERNANDES, 2015, s/p).

Diante destas questões, o ensino coletivo de violão emergiu como uma importante proposta para um ensino musical escolar significativo, pois

o ensino coletivo de instrumentos musicais vem se tornando uma metodologia de ensino utilizada por professores de diversos instrumentos musicais, com atuação em diferentes espaços desde escolas de Educação Básica, instituições religiosas, projetos sociais e até mesmo no Ensino Superior (Sá, 2016, p. 21)

Assim, as aulas de Música se transformaram em um ambiente colaborativo, onde os alunos, com suas diferentes vivencias musicais, tocam e aprendem uns com os outros e com o professor. Além da elaboração de atividades que envolvessem todos os alunos, foi fundamental que o educador musical assumisse uma postura de pesquisador, crítico e flexível, estando aberto as vontades e necessidades das turmas.

Quando os educandos têm consciência do processo em que estão engajados e conhecem mais profundamente a si mesmos, ao professor e aos colegas podem contribuir significativamente [...] Conhecendo [os] educandos, assim como suas atividades musicais anteriores e atuais na família e em suas comunidades, o educador pode construir os passos metodológicos e definir o conteúdo pedagógico com eles mais eficazmente (BARBOSA, 2006, p. 100$101)$. 
Apesar de existir um número considerável de publicação em relação à Educação Musical no Brasil, poucas são encontradas sobre uma metodologia para o ensino coletivo de violão, com músicas arranjadas para o estudo coletivo e aplicação de exercícios que possam ser adaptados. Por isso, é "caminhando que se faz o caminhol", pois, com cada turma e a cada ano, outras práticas foram sendo desenvolvidas: algumas foram aprimoradas; enquanto outras, abandonadas. Neste artigo, relata-se uma possibilidade de caminho dentre tantos outros que possam ser criados a partir das diversas realidades musicais.

Um dos primeiros movimentos foi aproveitar a curiosidade, o interesse e a empolgação dos alunos pelo instrumento. Afinal, as turmas do $3^{\circ}$ ano, $4^{\circ}$ e $5^{\circ}$ ano iriam aprender a tocar violão! Então, mergulhou-se nos estudos sobre o instrumento.

Nesse processo foi muito importante proporcionar uma vivência musical para os alunos através da audição de música instrumental, de assistir vídeos de bons violonistas, tanto nacional como internacional, de pesquisa e da exploração das possibilidades sonoras do instrumento. Mesmo que os alunos ainda não conhecessem a posição das mãos e os acordes, desafiá-los foi fundamental para que ampliassem suas ideias de música e desenvolvessem sua sensibilidade, expressividade, criatividade e autonomia.

A partir dos diferentes modos de interagir com a música - compondo, cantando e tocando - foram sendo realizadas várias atividades em torno de arranjos que eram elaborados pelo educador musical. Nesse sentido, destaca-se a importância do professor ter um conhecimento sobre música e, principalmente, tocar um instrumento para se tornar, de certa forma, um exemplo para os alunos. Muitos alunos desejam tocar 'que nem o professor'.

Exercícios de solfejo foram importantes para que os alunos se familiarizassem com o som do violão. Leitura rítmica e melódica também. Como no $1^{\circ}$ e no $2^{\circ}$ ano nessa mesma escola os alunos já estudam Flauta Doce Barroca com o mesmo professor já dominavam a leitura musical e não tiveram dificuldades nesse sentido. Após os exercícios psicomotores associados a músicas do folclore ou conhecidas da turma o próximo passo foi ensinar acordes e o uso das cifras. A metodologia empregada foi resultado de algumas tentativas frustradas, pois, entregar para os alunos uma folha impressa com os acordes já desenhados no diagrama ou a letra da música já com as cifras indicadas onde deveriam ser tocadas não obteve o resultado esperado. Esse também é um processo de construção que exige percussão corporal e exploração de diversos sons e tempos.

${ }^{1}$ Música "Enquanto houver sol”, Titãs. 
Quanto à notação musical, uma das atividades foi estudar apenas músicas em compasso quaternário para usar a figura semibreve que vale quatro tempos. Além de cantar junto com a turma, bater palmas e marcar o tempo com o pé, os alunos também tinham uma folha com a letra da música. Enquanto cantavam e batiam palma paravam e escreviam o acorde que deveria ser tocado no momento certo da canção escolhida.

Dessa forma as turmas assimilaram quando os acordes deveriam ser tocados e a duração de cada um deles. Depois de tocar várias vezes com a figura semibreve passou-se para a mínima e depois para a semínima, na mão direita que fazia o ritmo das canções. Isso auxiliou na hora das apresentações porque os alunos não erravam as batidas e os acordes soavam uníssonos.

Em cada momento é muito importante trabalhar elementos expressivos da música, como diferentes andamentos, articulações e dinâmicas e através de jogos e brincadeiras, incentivando os alunos a explorarem o violão com autonomia. Também é muito interessante estimular os alunos a criarem suas próprias formas de registros de suas aprendizagens musicais, como alternativa para auxiliar na memorização dos conteúdos estudados.

O ensino coletivo de violão envolve o trabalho coletivo, a solidariedade, a troca com os pares, o saber ouvir o outro e esperar sua vez. Também envolve esforço pessoal, pois a apresentação do grupo depende da performance individual. Por isso, através de vídeos e áudios, os alunos foram estimulados à prática individual do instrumento e a começarem a organizar sua rotina de estudo em casa, pois,

O ensino coletivo de instrumento musical permite e implica a troca de relações importantes para o desenvolvimento de cada um; ou seja, existe uma relação social de dependência, pois todos participam juntos de um mesmo discurso. Tendo isso em mente, uma das possibilidades de trabalho dentro de uma turma heterogênea é a do arranjo ou adaptação, de acordo com o nível de cada grupo de alunos da turma. (OLIVEIRA, 2010, p. 24-25 - grifo do autor).

Um dos pontos mais significativos dos estudos empreendidos nas aulas de Música são apresentações, pois, "todo artista tem que ir aonde o povo está ". Durante o ano letivo são realizadas pequenas apresentações e no mês de outubro, em comemoração ao Dia da Música, é realizado o evento "Tocando a Vida" em uma das casas de cultura da cidade, onde todos são envolvidos (equipe gestora, professores, alunos, funcionários, pais).

\footnotetext{
${ }^{2}$ Música "Nos bailes da vida", de Milton Nascimento.
} 
Figura 1 - Apresentação da turma do $5^{\circ}$ ano - Tocando a Vida

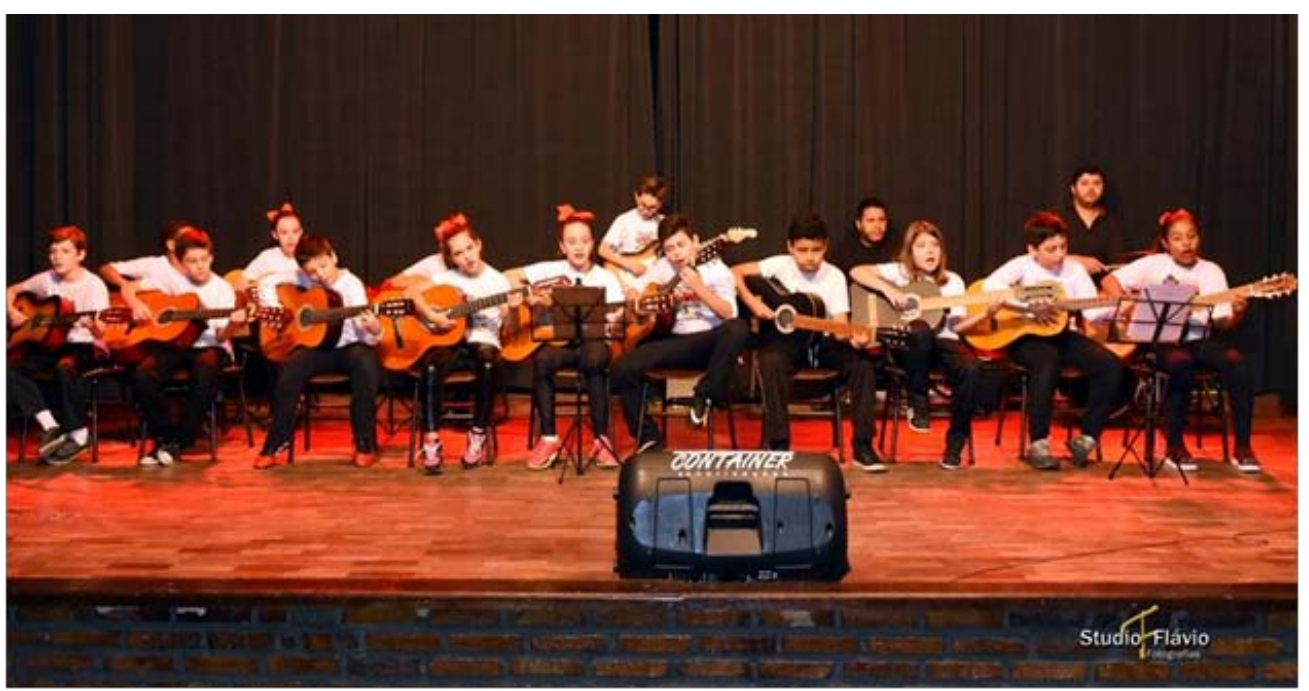

\section{Conclusão}

O trabalho envolvendo o ensino coletivo de violão na aprendizagem musical de alunos de anos iniciais é uma relevante ferramenta para o desenvolvimento dos conteúdos de Música no currículo da Educação Básica.

Com esse estudo conclui-se que ensinar Música através do ensino coletivo de violão proporciona muitos desafios musicais que possibilitam despertar nos alunos o desejo em aprender. Fazer música em grupo faz com os alunos desenvolvam suas experiências musicais de maneira colaborativa e busquem uma maior autonomia em suas aprendizagens.

Também constatou-se a importância do professor buscar formação em Educação Musical para que seja capaz de criar propostas criativas, de acordo com as necessidades de cada turma, assumindo uma postura de mediador das aprendizagens musicais de seus alunos, pois é preciso fazer música para aprender música. 


\section{REFERENCIAS}

AHMAD, Laila Azize Souto. Música No Ensino Fundamental: A Lei 11.769/08 e a Situação De Escolas Municipais De Santa Maria/RS. 168f. Dissertação (Mestrado em Educação) - UFSM, Santa Maria, 2011.

APPOLNÁRIO, F. Dicionário de metodologia científica: um guia para a produção do conhecimento científico. São Paulo: Atlas, 2004.

APPOLNÁRIO, F. Dicionário de metodologia científica: um guia para a produção do conhecimento científico. São Paulo: Atlas, 2004.

ARROYO, Margarete. Políticas educacionais, arte-educação e educação musical: um estudo na cidade de Uberlândia, MG. In: Encontro Anual da ABEM, 12, 2003, Florianópolis. Anais... Florianópolis: ABEM, 2003, p. 586-594.

BARBOSA, Joel. Rodas de Conversa na Prática do Ensino Coletivo de Bandas. In: Anais do II ENECIM - Encontro Nacional de Ensino Coletivo de Instrumento Musical. Goiânia: 2006, p.97-104.

BRASIL, Lei no 11.769 , de 18 de agosto de 2008. Altera a Lei no 9.394, de 20 de dezembro de 1996, Lei de Diretrizes e Bases da Educação, para dispor sobre a obrigatoriedade do ensino da música na educação básica. Brasília, DF, 2008.

DIAS, Sheila Graziele Acosta. A política de ensino para a arte no Brasil: a musicalização na educação infantil e o ensino da música nas séries iniciais do ensino fundamental. 218f. Dissertação (Mestrado em Educação) - UEM, Maringá, 2010.

FERNANDES, Rosângela. Ensino individual e coletivo de piano. In: XXII Congresso Nacional da Associação Brasileira de Educação Musical, Natal. Anais... ABEM, 2015, s/p.

GARDNER. Inteligências Múltiplas: a teoria na prática. Trad. Maria Adriana Veríssimo Veronese. Porto Alegre: Artes Médicas, 1995.

HENTSCHKE, Liane. Relações da Prática com a Teoria na Educação Musical. In: Encontro Anual da ABEM, 2, 1993. Anais. Porto Alegre, p.49-67, mai. 1993.

HIRSCH, Isabel Bonat. Música na Educação Básica: um survey com professores das séries finais do ensino fundamental e do ensino médio de escolas estaduais da região sul do Rio Grande do Sul. In: Encontro anual do ABEM, 16, 2007, Campo Grande-MS. Anais. Florianópolis:

ABEM, 2007.

LOUREIROR, Alícia Maria Almeida. O Ensino da Música na Escola Fundamental: Dilemas e

Plu 
Perspectivas. In: Revista Educação - UFSM. Edição: 2003 - vol. 28, nº 01. Disponível em: < http://coralx.ufsm.br/revce/revce/2003/01/a8.htm>. Acesso em 10 dez. 2017.

MATEIRO, Teresa da Assunção Novo. Educação musical nas escolas brasileiras: retrospectiva histórica e tendências pedagógicas atuais. In: Revista Arte-Online, v.3, mar./ago. 2000.

OLIVEIRA, Pedro Augusto Dutra de. O ensino coletivo de instrumento musical: explorando a heterogeneidade entre alunos de uma mesma turma. In: Revista Espaço Intermediário, São Paulo, v.1, n.2, p. 19-30, 2010.

PENNA, Maura. Professores de música nas escolas públicas de ensino fundamental e médio: uma ausência significativa. In: Revista da ABEM, Porto Alegre, v.7, p. 7-19, set. 2002.

QUEIROZ, Luis Ricardo Silva; MARINHO, Vanildo Mousinho. Práticas para o ensino da música nas escolas de educação básica. In.: Música na Educação Básica. Porto Alegre, v. 1, n. 1, outubro de 2009.

SILVA SÁ, Fábio Amaral da. Ensino coletivo de violão: uma proposta metodológica/ Fábio Amaral da Silva Sá. - 2016. Disponível em $<$ https://mestrado.emac.ufg.br/up/270/o/ F\%C3\%A1bio_Amaral_da_Silva_S\%C3\%A1-_Disserta\%C3\%A7\%C3\%A3o_Final.pdf $>$. Acesso em outubro de 2017.

TEIXEIRA BARRETO, M. S. Ensino Coletivo de Violão: Diferentes Escritas no Aprendizado de Iniciantes. 2008. Monografia de fim de curso de Licenciatura em Música - Instituto Villa-Lobos, Centro de Letras e Artes, Universidade Federal do Estado do Rio de Janeiro.

ZAGONEL, Bernardete. Música, Mídia e Educação. Gazeta do Povo, Curitiba, 7 mai. 2001.

Enviado em: 19 de março de 2019

Apreciado em: 15 de abril de 2019

Inserido em: 08 de maio de 2019 